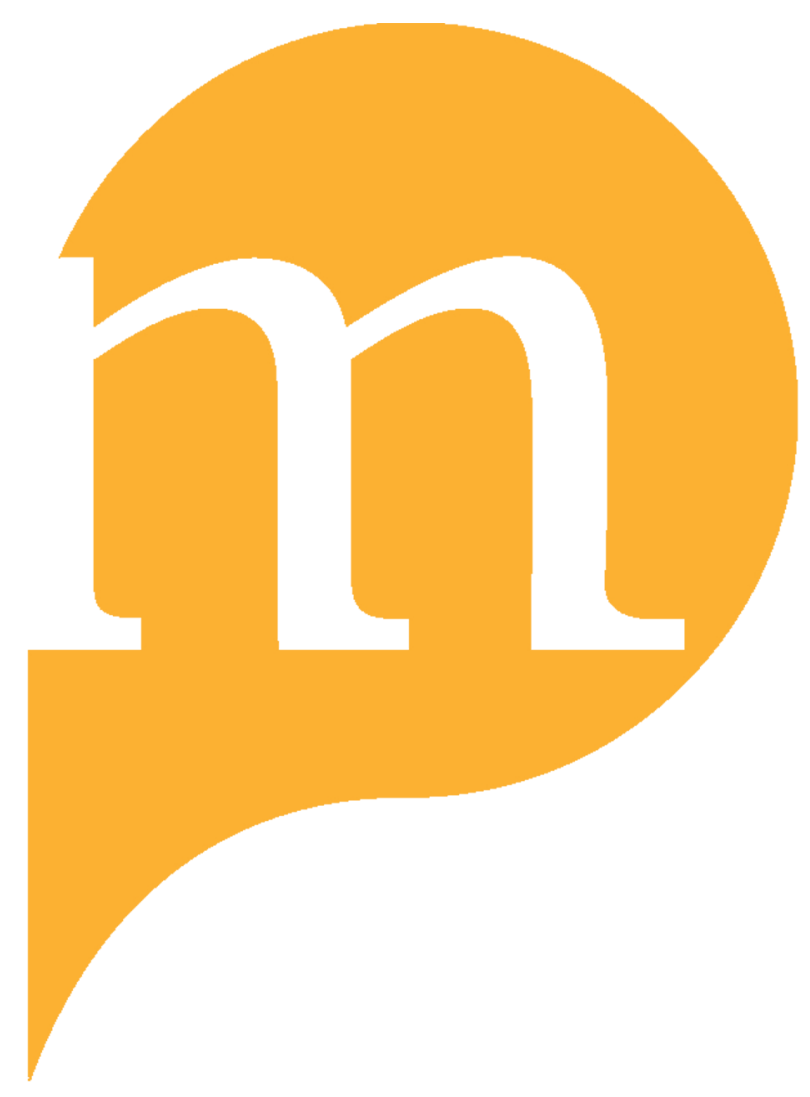

PROJECT MUSE 


\title{
Do Reasons for Attending College Affect Academic Outcomes? A Test of a Motivational Model From a Self-Determination Theory Perspective
}

\author{
Douglas A. Guiffrida \\ Martin F. Lynch \\ Andrew F. Wall \\ Darlene S. Abel
}

A survey of 2,520 college students was conducted to test relationships between academic success and college student motivational orientation, conceptualized from a self-determination theory (SDT) perspective, while also considering the moderating effects of background characteristics such as gender, socioeconomic status, racel ethnicity, and institutional type. Findings indicated that going to college to fulfill intrinsic motivation needs for autonomy and competence was positively associated with intention to persist and GPA but that motivation geared toward the fulfillment of relatedness needs had a more nuanced relationship to the outcome variables. Implications for recognizing the importance of motivational orientation in student affair research, theory, and practice are provided.

Tinto's (1993) theory of student persistence (first edition published in 1987) is among the most widely cited theories in the field of higher education and has been described as reaching "paradigmatic stature" (Braxton \& Lee, 2005, p. 108). Yet despite the prominent contributions of Tinto's theory in understanding the student departure process, the theory has also received criticism. In a recent review of the conceptual and empirical critiques of Tinto's theory, Guiffrida (2006) asserted the need for the theory to recognize the impact of student motivational orientation on student persistence decisions. As Stage
(1989) noted, Tinto's theory places a strong emphasis on student commitment but fails to describe the motivational orientations that lead to academic commitment. In his recent, comprehensive review of college retention research, Reason (2009) also highlighted the need to better understand relationships between student motivation and academic outcomes to increase our understanding of the college persistence puzzle.

Guiffrida $(2006,2009)$ argued that the principles of self-determination theory (SDT; Deci \& Ryan, 1991) provided an opportunity to advance Tinto's (1993) theory by recognizing relationships between motivational orientation and college student academic achievement and persistence. SDT is a theory of motivation, personality, and development that proposes that intrinsic motivation, or motivation derived purely from the satisfaction inherent in the activity itself, is more conducive to learning than extrinsic motivation, or motivation to achieve an external reward or to avoid a punishment. According to SDT, there are three primary psychological needs that, when satisfied, foster intrinsic motivation: (a) autonomy, which occurs when students choose to become engaged in learning because the subject and activities are closely aligned with their interests and values; (b) competence, which is the need to test and challenge one's abilities; and (c) relatedness, which is the need

Douglas A. Guiffrida is Associate Professor; Martin F. Lynch is Assistant Professor; Andrew F. Wall is Associate Professor; and Darlene S. Abel is a doctoral student; each at the Margaret Warner Graduate School of Education and Human Development, University of Rochester. 
to establish close, secure relationships with others. Although relatedness is posited to be a distinct need in itself, relationships often (but not always) provide the context in which the other two needs can be satisfied. SDT considers that motivation falls along a continuum, with more external forms of motivation at one end and more internal forms of motivation at the other, and that need-satisfying experiences can help to shift motivation from the external to the internal end of the continuum (Ryan \& Lynch, 2003).

Numerous studies have tested key SDT constructs in both lab-based and classroom settings, leading it to become one of the most empirically validated theories for understanding educational motivation (see Reeve, Deci, \& Ryan, 2004), and evidence is beginning to emerge that supports its relevance for education cross-culturally (e.g., Chirkov, 2009). However, the theory has not been applied extensively to understand college student academic achievement and persistence. A review of higher education research revealed only three studies that have examined relationships between intrinsic motivation and college student academic achievement and persistence (Côté \& Levine, 1997; Stage, 1989; Vallerand $\&$ Bissonnette, 1992) and none of the studies assessed motivational orientation in terms of the three basic psychological needs that SDT argues are central to human motivation. Additionally, research has not tested the SDT assertion that autonomy, competence, and relatedness are needs whose fulfillment leads to internal motivation for attending college, irrespective of student or institutional characteristics. The purpose of this study was to assess the relationship between intrinsic motivation for attending college as defined by SDT and academic success, while considering the possible moderating effects of student and institutional characteristics that prior research has shown to be related to college academic achievement and retention.

\section{COLLEGE STUDENT MOTIVATION AND RETENTION RESEARCH}

Although prior studies examining college student motivation (Côté \& Levine, 1997; Stage, 1989; Vallerand \& Bissonnette, 1992) all supported the importance of intrinsic motivation to college student success, only Vallerand and Bissonnette's study examined motivation explicitly from an SDT framework. However, Vallerand and Bissonnette did not assess the need for relatedness, which is a salient limitation and substantial gap that exists in the literature given recent research emphasizing the important role that relationships with college peers, faculty, and family and friends from home have in facilitating college success (for a review see Guiffrida \& Douthit, 2010).

Conceptually, it is logical that motivation to attend college to fulfill relatedness needs may have a more complex relationship to college success than autonomy and competence, depending on the type, quality, and purpose of the relationship. Indeed, research has provided psychometric evidence for the complexity of the relatedness construct with respect to academic motivation (Guiffrida, Gouveia, Wall, \& Seward, 2008), and careful attention must be paid as to whether a particular form of relatedness motivation reflects a genuine satisfaction of the need for relatedness, or some other compensatory process. For example, students who attend college with a motivational orientation to fulfill relatedness needs with faculty may be more academically successful, given research indicating the importance of faculty/student relationships to academic achievement (Astin, 1996; Pascarella $\&$ Terenzini, 2005), than students whose motivational orientation to attend college is to fulfill relatedness needs with college peers.

Prior research also indicates that students can be motivated to attend college to fulfill relationships at home for two very different 
reasons: out of fear of losing these relationships, or to give back to others from home (Guiffrida et al., 2008). From an SDT perspective, motivation to avoid losing a relationship is more likely to be an extrinsic form of motivation, whereas giving back would be considered on the more internalized side of the motivation continuum (see Deci \& Ryan, 2000; Ryan, Sheldon, Kasser, \& Deci, 1996; Vansteenkiste, Lens, \& Deci, 2006). Based on SDT, it is likely that motivation to attend college to give back to one's family and friends from home (which reflects the mutuality characteristic of true relatedness, as a basic need) would be positively associated with college success while motivation to attend college to avoid losing relationships at home (which more likely reflects compensatory or introjected processes) would be negatively associated with academic success. These potentially complex relationships between relatedness motivation and college academic success have not, to this point, been empirically tested.

In addition to the failure of prior college student motivation research to examine relatedness motivation, prior research has also not tested whether or how student or institutional characteristics that have been identified as correlates to student success impact the relationship between motivational orientation and academic outcomes. SDT assumes that autonomy, competence, and relatedness are universal needs whose fulfillment leads to internal motivation in a given domain of activity, and that this association should not be moderated by student or institutional characteristics (Deci \& Ryan, 1991); however, empirical research has not explicitly tested these assumptions.

To test the SDT premise that relationships between intrinsic motivation and academic outcomes are not moderated by student background or institutional characteristics, we identified several salient institutional and student characteristics related to college student academic achievement and persistence to include as moderating variables in our model. One of the strongest correlates of persistence is the type of institution a student attends. Using census data from 1967-2000, Mortenson (2005) found that students attending 2-year colleges are significantly less likely to graduate from college than students attending 4-year colleges. In the current study, we included students from both and 2-year and 4-year institutions to assess whether institutional type would moderate the relationship between student motivational orientation and academic success.

We also identified several student background characteristics that are strongly related to college student academic achievement and persistence. One of the most important of these background characteristics is socioeconomic status (SES). Research indicates that family income level and parental education are strongly positively correlated with college student academic success (Betts \& Morrell, 1999; Mortenson, 1993; Pascarella \& Terrenzini, 2005; U.S. Department of Education, 1998). A second student background characteristic that is strongly correlated with college student success is gender, with females graduating at significantly higher rates than males (Nora, Barlow, \& Crisp, 2005). A third student background characteristic related to college student success is student race/ethnicity, with White and Asian American students graduating from college at much higher rates than African American, Latino, and Native American students (Mortenson, 2005). Underrepresented students of color are also likely to have lower grade point averages than White and Asian American students, even after controlling for variables such as SAT scores, high school GPA, SES, school selectivity, and academic major (Bowen \& Bok, 1998). Additionally, prior research suggests that some students of color may be motivated to attend college for 
different reasons than many of their White peers (Phinney, Dennis, \& Osario, 2006), which makes race/ethnicity a significant variable to include when testing for potential moderators of the relationship between motivation and academic outcomes.

To summarize, while prior studies support the relationships between intrinsic motivation and college student academic success, research has not tested this relationship using the three basic needs outlined by SDT (autonomy, competence, \& relatedness). In particular, research has not examined the relationship between relatedness motivation and college student academic outcomes. Additionally, prior research with college students has not yet tested the SDT assertion that relationships between intrinsic motivation and academic outcomes are universal and unaffected by institutional or student characteristics. The purpose of this study was to test relationships between college student motivational orientation and academic success while accounting for background characteristics such as gender, SES, race/ ethnicity, and institutional type. Specifically, we tested the following research questions:

1. What are the direct relationships between student motivation, conceptualized in terms of basic needs for autonomy, competence, and relatedness, and the student academic outcomes of GPA and intent to persist?

2. Are these relationships moderated by variables such as student SES, gender, or race/ethnicity, or by the type of educational institution the student is attending?

Based on SDT, our hypotheses regarding the first question are that student motivation based on autonomy and competence will be positively related to student outcomes, but that motivation based on relatedness will have a more nuanced association with outcomes: while motivation to give back to one's family will have positive associations with GPA and persistence intentions, motivation to maintain or keep up one's relationships with family and friends from home may reflect a more external (or introjected) orientation and, therefore, be associated with negative outcomes. Motivation to affiliate with professors is expected to be positively associated with academic outcomes, but motivation to affiliate with college peers, while in itself reflecting a striving toward relatedness, may be more problematic with regard to the academic outcomes assessed in this study. Our hypothesis regarding the second research question is that the association between student motivation and academic outcomes will not be moderated by student or institutional variables. The results are intended to advance student retention theory and practice by providing student affairs professionals with a more nuanced understanding of relationships between college student motivation and academic outcomes. Additionally, this study is intended to extend the current literature on SDT in educational contexts by attending to race/ethnicity, SES, gender, and type of college as potential moderators of the relationship between student motivation and academic outcomes.

\section{METHODS}

A web-based survey was completed by students from two diverse colleges located in the Northeastern United States: a large community college (enrollment 20,000) located in an urban center; and a small, regional public 4-year liberal arts college (enrollment 5,800) located in a rural area. The 4-year college serves mostly undergraduates $(90 \%$ of total enrollment), while also offering some master's degree programs that are largely related to educational occupations. According to Upcraft and Wortman (2000), there are many advantages to web-based surveys, including 
reducing participant time and fatigue, and providing an increased sampling pool when compared to traditional paper-and-pencil or phone surveys. Because the sample consisted of college students, all of whom had access to the internet (as well as college e-mail accounts), sampling bias resulting from participants not having internet access was avoided (Solomon, 2001). All full-time students at both institutions received an e-mail invitation describing the study with a link to a Web site hosting the surveys. Students were notified that they were under no obligation to participate but that those who completed the survey would be entered to win an iPod. Two weeks later, students who had not yet participated received a follow-up e-mail invitation to participate in the online survey.

\section{Participants}

A total of 2,520 students completed the survey (4-year college, $n=962$; community college, $n=1,558)$. Listwise deletion was used so that only students who completed all questions in the survey were included in the sample. Table 1 presents demographic information regarding the participants. Response rates were approximately $25 \%$ for the 4 -year college and $13 \%$ for the community college. These response rates, while seemingly low compared to traditional paper-and-pencil surveys, are consistent with other online surveys used in student affairs research (see Dey, 1997; Greenlaw \& Brown-Welty, 2009; Sax, Gilmartin, \& Bryant, 2003) and provide a much more diverse sample than had a smaller subpopulation of students at each college been selected (e.g., students in one particular course or major). Approximately 68\% of the sample was female (community college, $n=68 \%$; 4-year, $n=68 \%$ ), which was higher than the general student population of females at both institutions (community college, $n=53 \%$; 4-year, $n=55 \%$ ). Students of color represented $22 \%$ of the sample (community college, $n=23.9 \%$; 4-year, $n=18.8 \%$ ), which was slightly lower than the overall percentage of students of color enrolled at the community college $(28 \%)$ and higher than the overall percentage of students of color at the 4-year college (16\%). As with most survey research conducted with college students, academically high-achieving students were slightly overrepresented in the sample (Dey, 1997). Approximately 4\% of respondents self-reported their GPA to be less than 2.1; $12 \%$ reported a GPA between 2.1 and 2.5; the remaining students indicated a GPA over 2.5.

\section{Measures}

Participants completed a questionnaire that collected information regarding the four moderating variables: SES, race/ethnicity, gender, and which institution they attended (2-year or 4-year). The questionnaire also asked students to self-report their college GPA (the first dependent variable). In their extensive review of college student research, Pascarella and Terrenzini (2005) concluded that college grades were one of the best predictors of student persistence, degree completion, and graduate school enrollment. Additionally, in their meta-analysis, Kuncel, Crede, and Thomas (2005) found that self-reported grades provide reasonably accurate reflections of actual grades, especially for students with high ability and good grade point averages, and were generally predictive of future grade point averages. In fact, they found that GPAs have the highest correlation with school records when compared against other information reported by students.

While GPA provides a reasonably good indication of college success, not all students with high GPAs intend to persist and not all students with low GPAs intend to leave college (Pascarella \& Terrenzini, 2005). Therefore, we also assessed student intention to persist 
TABLE 1.

Demographic Characteristics of Participants

\begin{tabular}{cccc}
\hline Total & $2-$ Year & $4-Y e a r$ \\
$(N=2,520)$ & $(n=1,558)$ & $(n=962)$ \\
$\% N$ & $\% n$ & $\% n$ \\
\hline
\end{tabular}

\begin{tabular}{lrrr}
\hline $\begin{array}{l}\text { Gender } \\
\text { Female }\end{array}$ & 68.5 & 68.7 & 68.4 \\
Male & 31.4 & 31.3 & 31.6 \\
Age(years) & & & \\
$18-24$ & 74.8 & 66.5 & 88.1 \\
$25-30$ & 10.0 & 12.1 & 6.4 \\
$31-40$ & 8.6 & 12.1 & 2.9 \\
Over 40 & 6.3 & 8.9 & 2.0 \\
Other & 0.4 & 0.4 & 0.5
\end{tabular}

Academic Standing

$\begin{array}{lrrr}\text { Freshman } & 30.2 & 36.4 & 20.3 \\ \text { Sophomore } & 41.1 & 55.2 & 18.4 \\ \text { Junior } & 10.3 & \text { NA } & 26.9 \\ \text { Senior } & 12.4 & \text { NA } & 32.4 \\ \text { Other } & 6.0 & 8.4 & 2.0\end{array}$

Cumulative College GPA

$\begin{array}{lrrr}<2.1 & 3.2 & 3.6 & 2.7 \\ 2.1-2.5 & 11.7 & 10.7 & 13.3 \\ 2.6-3.0 & 25.9 & 24.0 & 28.9 \\ 3.1-3.5 & 31.4 & 29.8 & 34.0 \\ 3.6-4.0 & 25.2 & 28.4 & 20.0 \\ \text { Other } & 2.6 & 3.5 & 1.1\end{array}$

College Residence

$\begin{array}{lrrr}\text { On campus } & 24.7 & 4.1 & 58.0 \\ \begin{array}{l}\text { Off campus with } \\ \text { friends }\end{array} & 23.1 & 21.4 & 26.0 \\ \begin{array}{l}\text { Off campus with } \\ \text { parents or family }\end{array} & 52.2 & 74.5 & 16.0\end{array}$

SAT Score

$\begin{array}{lrrr}0-990 & 17.0 & 15.7 & 19.2 \\ 1000-1090 & 17.7 & 14.5 & 22.7 \\ 1100-1190 & 16.6 & 12.5 & 23.3 \\ 1200-1290 & 10.5 & 9.1 & 12.7 \\ 1300-1390 & 4.3 & 3.9 & 5.0 \\ 1400-1490 & 1.3 & 1.2 & 1.6 \\ 1500-1600 & 0.5 & 0.6 & 0.2 \\ \text { Other } & 32.1 & 42.5 & 15.4\end{array}$

\begin{tabular}{|c|c|c|c|}
\hline & $\begin{array}{c}\text { Total } \\
(N=2,520)\end{array}$ & $\begin{array}{c}2-Y e a r \\
(n=1,558)\end{array}$ & $\begin{array}{c}\text { 4-Year } \\
(n=962)\end{array}$ \\
\hline \multicolumn{4}{|l|}{ High School GPA } \\
\hline$<61$ & 0.8 & 1.2 & 0.1 \\
\hline $61-70$ & 2.7 & 3.1 & 1.9 \\
\hline $71-80$ & 18.2 & 22.1 & 11.7 \\
\hline $81-90$ & 47.6 & 44.5 & 52.6 \\
\hline $91-100$ & 23.1 & 19.8 & 28.5 \\
\hline Other & 7.7 & 9.2 & 5.2 \\
\hline \multicolumn{4}{|l|}{ Ethnicity } \\
\hline White & 78.1 & 76.1 & 81.2 \\
\hline African American & 7.3 & 9.4 & 4.0 \\
\hline Hispanic American & 5.0 & 5.4 & 4.4 \\
\hline Asian American & 2.2 & 2.2 & 2.1 \\
\hline Native American & 0.7 & 0.9 & 0.3 \\
\hline Multiethnic & 2.9 & 3.1 & 2.5 \\
\hline International Student & 3.9 & 2.9 & 5.5 \\
\hline \multicolumn{4}{|l|}{ Family Income Level } \\
\hline Below $\$ 21,000$ & 18.5 & 21.8 & 13.1 \\
\hline$\$ 21,000$ to $\$ 39,000$ & 19.6 & 20.5 & 18.2 \\
\hline$\$ 39,001$ to $\$ 63,000$ & 23.7 & 24.3 & 22.7 \\
\hline$\$ 63,001$ to $\$ 88,000$ & 17.1 & 15.9 & 19.0 \\
\hline$\$ 88,001$ to $\$ 113,000$ & 11.8 & 9.6 & 15.4 \\
\hline Over $\$ 113,000$ & 6.2 & 4.4 & 8.9 \\
\hline Other & 3.1 & 3.4 & 2.7 \\
\hline \multicolumn{4}{|l|}{ Parental Education Level } \\
\hline $\begin{array}{l}\text { Did not complete } \\
\text { high school }\end{array}$ & 6.8 & 8.2 & 4.5 \\
\hline High school degree & 25.4 & 26.7 & 23.2 \\
\hline Some college & 17.2 & 17.1 & 17.3 \\
\hline Associate's degree & 13.0 & 13.6 & 12.1 \\
\hline Bachelor's degree & 21.2 & 20 & 23.2 \\
\hline Graduate degree & 16.0 & 13.9 & 19.4 \\
\hline Other & 0.4 & 0.4 & 0.4 \\
\hline
\end{tabular}


(the second dependent variable) using items that were developed and used in a prior study conducted by Hardre and Reeve (2003). The three items, which participants responded to using a 7-point Likert-type scale from 1 (does not correspond at all) to 7 (corresponds exactly), were as follows:

1. I sometimes consider dropping out of school.

2. I intend to drop out of school.

3. I sometimes feel unsure about continuing my studies year after year.

Items were reverse scored to indicate intent to persist. Prior research conducted by Vallerand, Fortier, and Guay (1997) found that student responses to the first two items strongly predicted actual dropout behavior 1 year later. In a subsequent study, Hardre and Reeve (2003) added the third item to increase the scope and reliability of the outcome measure and reported acceptable internal consistency $(\alpha=.79)$ among the three items. Internal consistency with the current sample was also acceptable $(\alpha=.78)$. For exploratory purposes, we also tested the association between student GPA and intention to persist (IP) with the current sample by correlating the mean of the three IP items with GPA. The results $(r=.22$, $p<.01)$, while indicating a positive association between IP and GPA, also indicated that this relationship is relatively weak, which supports our decision to assess both outcome variables.

In addition to completing the demographic questionnaire and the questions to assess intentions to persist and GPA, participants also completed the following scales to assess the independent variables (see Appendix A for a full list of variables):

1. Competence Motivation scale, which is derived from the Academic Motivation Scale (AMS; Vallerand et al., 1992). The AMS assesses reasons for attending college from an SDT perspective. We used the four items from the AMS subscale that assessed intrinsic motivation toward accomplishment. While the AMS uses the term toward accomplishment to label this subscale rather than competence motivation, a review of the scale development article (Vallerand et al., 1992) indicated that the subscale provides an accurate measure of competence motivation from an SDT perspective. Participants were asked to rate their level of agreement with each of the four sentence stems that completed the statement, "I go to college to . .." using a 7-point Likert-type scale from 1 (does not correspond at all) to 7 (corresponds exactly). The items included:

a. for the pleasure I experience while surpassing myself in my studies.

b. for the pleasure I experience while I am surpassing myself in one of my personal accomplishments.

c. for the satisfaction I feel when I am in the process of accomplishing difficult academic activities.

d. because college allows me to experience a personal satisfaction in my quest for excellence in my studies.

In the current sample, internal consistency reliability was acceptable among the four competence motivation items $(\alpha=.88)$.

2. The Need for Relatedness at College Questionnaire (NRC-Q; Guiffrida et al., 2008), which assesses the degree to which students attend college to fulfill needs for relatedness with others. The scale consists of 12 items assessing the following four relationships: college peers (relatedness to school / peers; 3 items, $\alpha=.82$ ), faculty/ staff (relatedness to school / faculty; 3 items, $\alpha=.84$ ), and two separate subscales that assess relationships with family and friends 
from home. These two subscales focus on different reasons that students might attend college: (a) to maintain relationships with people from home (relatedness to home / keep-up; 3 items, $\alpha=.85$ ), or (b) to give back to others from home (relatedness to home / altruistic; 3 items, $\alpha=.75$. Consistent with the AMS, participants were asked to rate their level of agreement with each sentence stem that completed the statement, "I go to college to ..." using a 7-point Likert-type scale from 1 (does not correspond at all) to 7 (corresponds exactly).

3. Autonomous Motivation Scale, which consisted of four questions designed specifically for this study to assess autonomous reasons for attending college. These items were derived from an extensive review of literature that described the construct of autonomy from an SDT perspective (e.g., Deci \& Ryan, 1991; Reeve et al., 2004; Ryan \& Powelson, 1991) along with a review of a related assessment instrument that measured feelings of autonomy (Deci, Koestner, \& Ryan, 2001). Content validity for the autonomy items was determined by the literature review described above and by consulting with three experts in SDT (including one of the founders of the theory). Participants were asked to rate their level of agreement with each sentence stem that completed the statement, "I go to college ..." using a 7-point Likert-type scale. The four items were as follows:

a. because I enjoy learning new things.

b. for the pleasure I experience in broadening my knowledge about subjects which appeal to me.

c. because my studies allow me to continue to learn about many new things that interest me. d. out of personal choice.

In the current sample, items had an acceptable internal consistency reliability $(\alpha=.85)$.

\section{DATA ANALYSIS}

Data were collected using an online survey tool, downloaded into a Microsoft Excel ${ }^{\circ}$ spreadsheet, and imported into SPSS (version 15.0). Descriptive data analysis and data cleaning were completed in SPSS, after which data were imported into AMOS (version 7.0). Structural equation modeling (SEM) was then conducted using AMOS to test the structural pathways between the motivational orientations (autonomy, competence, and relatedness) and the academic outcomes (intention to persist and GPA). We chose to use SEM because it allowed us to examine the linear relationships between the independent latent variables (relatedness, competency, autonomy) and the two dependent variables (intention to persist, GPA) simultaneously, using cross-sectional data (Byrne, 2001). Similarly, we were interested in the ability of SEM to test for moderation effects by assessing the fit of our hypothesized model for the entire sample and for various subsamples.

Structural equation modeling was completed by developing a hypothesized model from our review of the SDT literature and preliminary linear regression analysis (see Figure 1) and then testing the hypothesized model empirically. We also tested whether the overall model would be moderated by gender, SES, race/ethnicity, or institutional type (2-year or 4-year institution). Tests of moderation were conducted by splitting the sample into groups by gender (male, $n=792$; female, $n=1,728$ ), SES (high, or $+1 S D, n=382$; low, or $-1 S D, n=541$ ), race/ethnicity (White, $n=1,966$; students of color, $n=554$ ), or institutional type (2- 


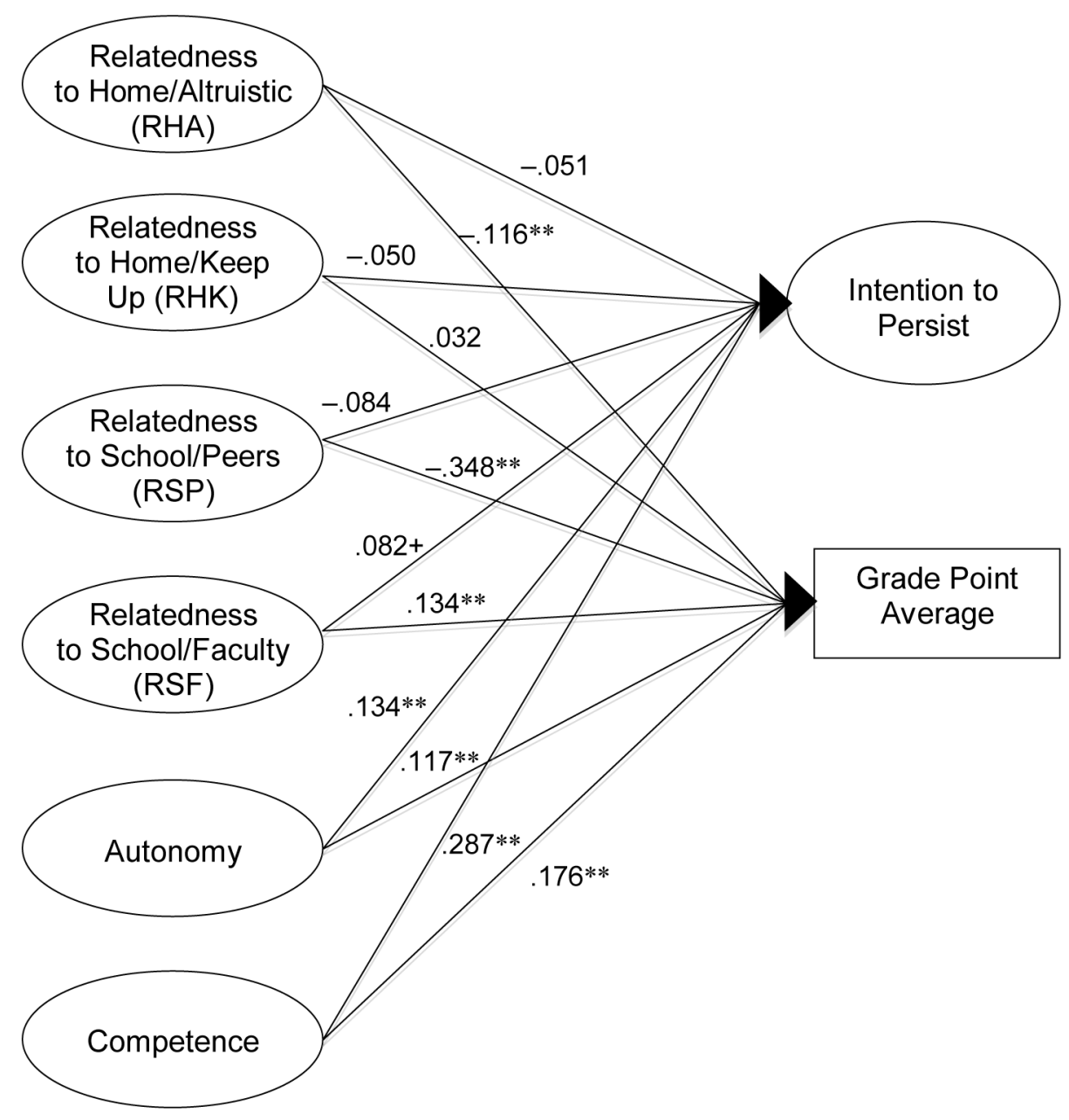

FIGURE 1. Structural Equation Model

$$
{ }^{+} p<.08 . \quad * p<.05 . \quad * * p<.01 .
$$

year, $n=1,558$; 4-year, $n=962$ ), and then performing separate multigroup analyses for each potential moderator in AMOS to test for invariance across groups (see Meyers, Gamst, \& Guarino, 2006).

\section{RESULTS}

Results for the full model are presented in Table 2 (see also Figure 2). Results for the overall motivational model (see Table 2, Model 1) indicated model fit, $\chi^{2}(d f)=1,778.50$ (224), $p<.001$; comparative fit index $(\mathrm{CFI})=.953$; incremental fit index $(\mathrm{IFI})=.953$; root mean squared error (RMSEA) $=.052$. Consistent with SDT, the results indicated that autonomy and competence were positively associated with IP and GPA. As an example, the standardized coefficient for the path between competence motivational orientation and IP was .29 $(p<.01)$, indicating that those who attended college motivated by the need for competence were more likely to report intentions to persist.

As hypothesized, the relationships between the four types of relatedness and the outcome 


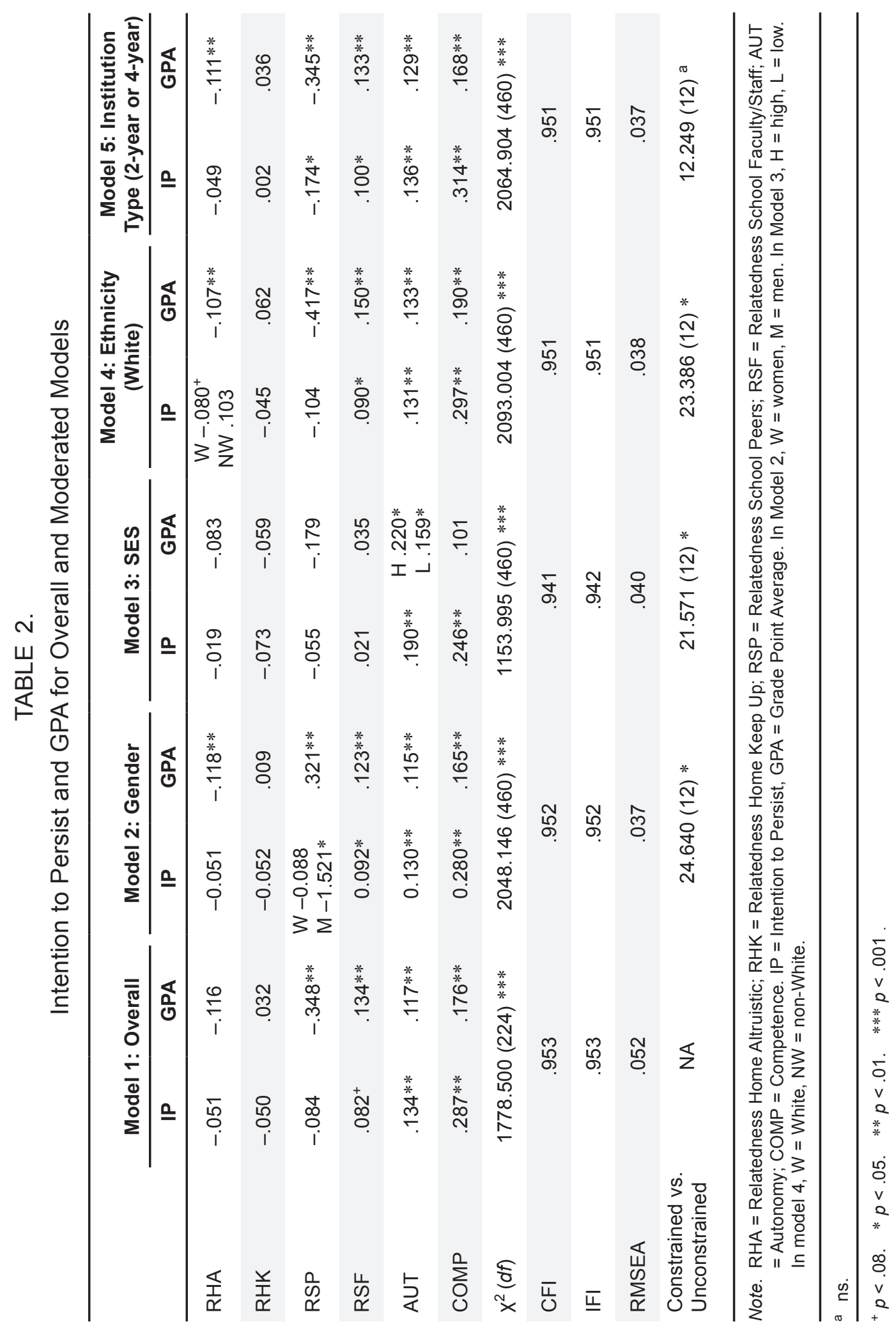




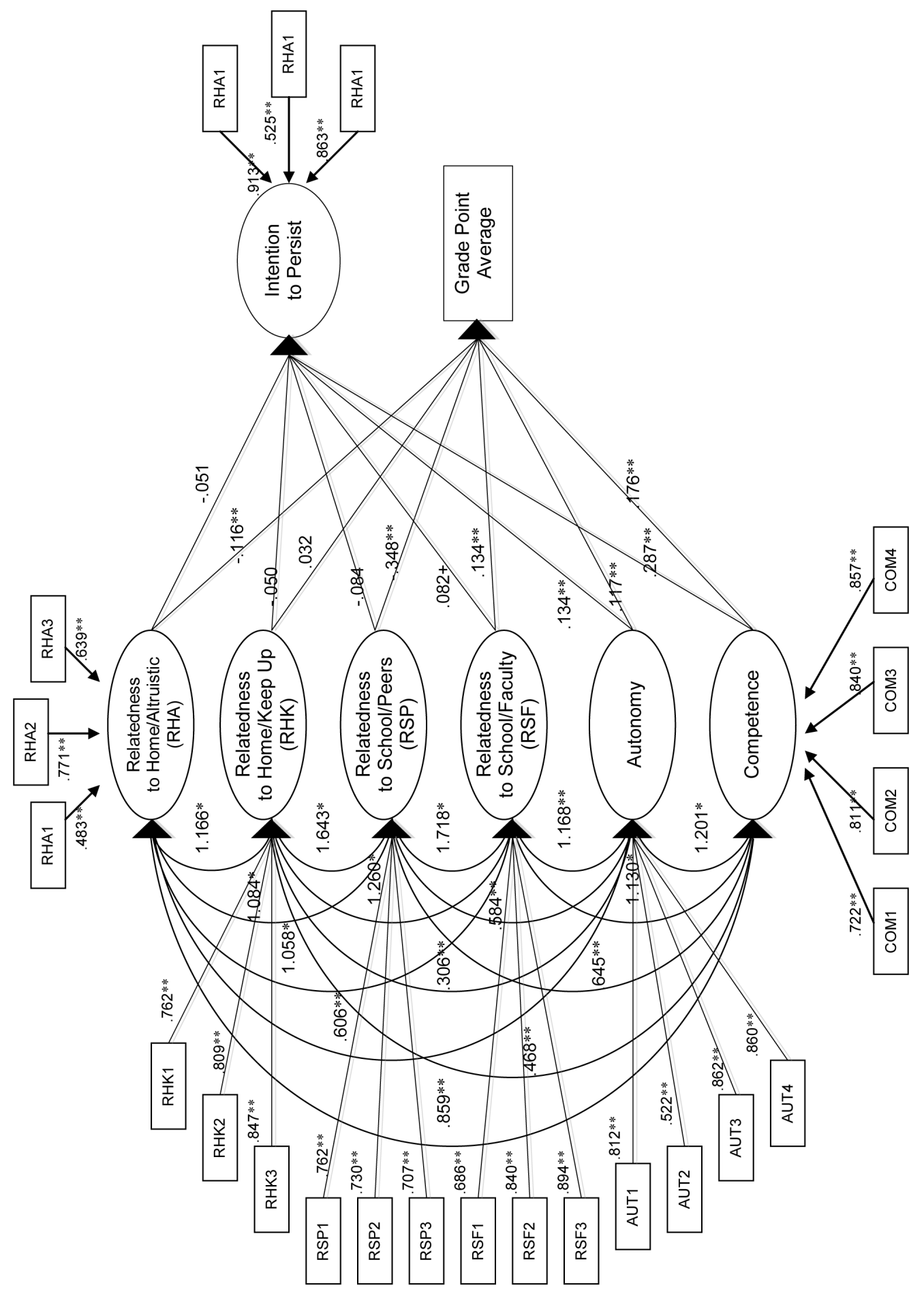

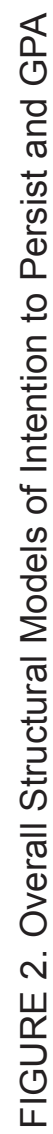


variables were more complex than those for autonomy and competence. The four types of relatedness were as follows: (a) relatedness to school/faculty (RSF), indicating the desire to connect with college faculty/staff as a strong motivation for attending college; (b) relatedness to school/peers (RSP), indicating the desire to connect with other college students as a motivation for attending college; (c) relatedness to home / altruistic (RHA), indicating the desire to give back to people from home or make them proud as a motivation for attending college; and (d) relatedness to home / keep up (RHK), indicating the desire to maintain relationships with family and friends from home by attending college. Although none of the four types of relatedness were significantly associated with IP, RSF was marginally significantly associated with IP $(.082, p<.08)$. There were, however, significant associations between the types of relatedness and GPA. In fact, the path between RSP and GPA, the strongest path in model, was negative and significant $(-.35, p<.01)$, indicating that going to college to fulfill relatedness needs with peers was negatively associated with GPA. Conversely, the path between RSF and GPA was positive and significant (.13, $p<.01$ ), indicating that going to college to fulfill relatedness needs with faculty and staff was positively associated with GPA.

In Model 2, we tested whether gender moderated the overall model (Model 1). Accordingly, we split the sample into two groups: men $(n=792)$ and women $(n=1,727)$. As with Model 1, model fit was acceptable, $\chi^{2}(d f)=2,048.15$ (460), $p<.001$; CFI = .952; IFI $=.952 ;$ RMSEA $=.037$. Following the procedures outlined by Meyers et al. (2006), we then performed a nested model comparison, which uses a chi-square test to examine differences between the free model, in which parameters were free to vary, and the equal model, in which parameters (in this case, the structural pathways from the independent variables to the outcome variables) were constrained to be equal across the two groups. The nested model comparison was significant, $\chi^{2}(d f)=24.64$ (12), $p<.05$, indicating that gender moderated at least one of the pathways in our overall motivational model (Model 1).

To specify which pathway(s) differed, we examined the critical ratios for differences between parameters in the free model. Because this is a chi-square distribution, values of 1.96 or higher are deemed significant (Meyers et al., 2006). The pathway showing significant differences in this model was between RSP and IP. This path was significantly more negative for men $(-1.521, p<.05)$ than for women $(-0.09, \mathrm{~ns})$, indicating that men who were motivated to attend college to be connected to peers were significantly less likely than women (motivated for the same reason) to report intentions to persist. While other findings from Model 2 were generally consistent with the findings from Model 1, the path between RHA and GPA, and RSF and IP were significant in Model 2, although they did not reach significance in Model 1.

We next tested whether paths in the overall model would be moderated by SES, a composite of family income and parental education (see Table 2, Model 3). We split the sample into high SES (+1 SD) and low SES $(-1$ SD). Again, model fit was acceptable, $\chi^{2}(d f)=1,153.995$ (460), $p<.001$; CFI = .941; IFI $=.942$; RMSEA $=.040$; and the nested model comparison showed a significant difference between the free and equal models, $\chi^{2}(d f)=21.571$ (12), $p<.05$, indicating that SES moderated at least one of the pathways in our overall motivational model (Model 1). Examining the critical ratios for differences revealed that SES moderated the path between Autonomy and GPA such that the path was more positive for those with high SES compared to those with low SES. This result 
suggests that going to college to fulfill needs for autonomy was more important to the success of higher SES students than lower SES students. One other noteworthy observation from Model 3 was that the relatedness motivational variables were not significantly associated with either of the outcome variables and that competence was no longer associated with GPA as it had been in Model 1, indicating that SES plays an important moderating role in the motivational model.

The third background characteristic we tested for moderation effects was race/ethnicity (see Model 4), for which we split the sample into two groups: White students $(n=1,966)$ and students of color $(n=554)$. Again, model fit was acceptable, $\chi^{2}(d f)=2,093.004$ (460), $p<.001$; $\mathrm{CFI}=.951$; IFI $=.951$; $\mathrm{RMSEA}=.038$; and the nested model comparison showed significant differences between the free and equal models, $\left.\chi^{2}(d f)=23.396(12), p<.05\right)$. The pathway that differed for race/ethnicity was between RHA and IP, such that the path was marginally significant and negative for Whites and nonsignificant and positive for students of color. White students who indicated motivation for attending college to give back to others at home reported less intention to stay in college compared to students of color who attended college for the same reason. This result suggests that altruism with regard to one's home community tended to be a negative academic motivator for Whites compared to students of color. The other differences between Model 4 and Model 1 included the fact that the pathways from RHA to GPA and from RSF to IP were significant in Model 4.

The fourth moderation effect examined was whether attendance at a 2-year or 4-year institution moderated the structural relations obtained in the original motivational model. Model fit was acceptable, $\chi^{2}(d f)=2,064.904$ (460), $p<.001$; CFI $=.951$; IFI $=.951$; RMSEA $=.037$; however, unlike the other models that tested for moderating effects of background characteristics, the nested model comparison for model 5 was not significant, $\chi^{2}(d f)=12.249(12)$, ns. This indicates that attendance at a 2-year or 4-year institution did not moderate the relationships between the motivational variables (autonomy, competence, and relatedness) and the outcome variables (intention to persist and GPA). The proposed model worked equally well, regardless of institutional type.

\section{DISCUSSION}

The results of this study suggest that important relationships exist between college student motivational orientation and academic success. Consistent with the tenets of SDT, results of the structural equation modeling indicated that students who attended college motivated by intrinsic needs for autonomy and competence were more likely to have higher GPAs and greater intentions to persist than students who were not motivated to attend college to fulfill these intrinsic needs. In this respect, SDT contributes to our understanding of college student academic achievement and persistence and, as noted by Guiffrida (2006), provides potential for advancing Tinto's (1993) theory.

The results, however, also indicate that SES moderated the relationships between autonomy and competence and the outcome variables. Autonomy was more important to the success of higher SES students than to that of lower SES students. This was somewhat surprising given that research has demonstrated that autonomy is a necessary component to intrinsic motivation (see Reeve et al., 2004). While all students appear to benefit from studying subjects that are intrinsically interesting to them, higher SES students may have the luxury of benefiting from this intrinsic form of motivation more than lower SES students, whose motivations 
may also be influenced by financial needs.

As hypothesized, the results also indicated that the relationships between relatedness and academic achievement and intentions to persist were more complex than they were for autonomy and competence. While attending college to fulfill relatedness needs was not associated with intentions to persist in the overall model, it was associated with GPA. Specifically, going to college to fulfill relatedness needs with peers was strongly negatively associated with GPA. According to SDT (Deci \& Ryan, 1991), the desire to establish relationships with peers is ordinarily an intrinsic motivation and intrinsic forms of motivation are generally positively associated with academic success. It is likely, however, that students who emphasized relationships with peers as their motivation for attending college may have done so at the expense of the time they devoted to academics. The fact that there was not a negative association between relatedness at school / peers and intention to persist suggests, though, that while these peer relationships provide potential to negatively impact GPA, the relationships may also support (or, at least, not undermine) persistence by providing social integration as outlined by Tinto (1993).

Interestingly, the results also indicated that attending college to fulfill relatedness needs with peers has a larger negative impact on the academic success of men than on that of women. From an SDT perspective, it is important to explore the possibility that motivation for peer relationships needs to be further examined conceptually, for example, by assessing the quality of relationships with peers prior to going to college. It is possible that those who go to college to establish relationships do so from a compensatory or deficit position, which may have a more complicated impact on college outcomes. Alternately, it is possible that women may be better able to integrate and utilize their peer relationships in ways that foster their academic success.

The results also indicate that going to college to fulfill relatedness needs with faculty and staff was positively associated with GPA. Prior research has overwhelmingly supported the importance of strong faculty-student relationships to college success (see Astin, 1996; Pascarella \& Terenzini, 2005). It is natural, therefore, that students who attend college to fulfill needs to connect with faculty and staff would be most likely to actually establish these relationships and, therefore, benefit from these relationships by earning higher GPAs. Further, the desire to associate with faculty may in itself be an indicator of the seriousness of one's academic intentions. While much research has supported the need for institutions of higher education to develop programs to actively engage faculty with students, these results indicate that strong faculty-student relationships may also be a function of student motivation.

Another finding of interest regarding relatedness needs as motivation for attending college emerged when examining the associations between relatedness needs to home and the outcome variables. In this study, based on the prior work of Guiffrida et al. (2008), we were able to differentiate between two types of relatedness needs to home that provide motivation for students to attend college: (a) to maintain relationships with family and friends from home (keeping up), or (b) to give back to others from home. From an SDT perspective, keeping up would be considered a more extrinsic form of motivation because the activity is motivated by the fear of losing a relationship; whereas giving back would be considered on the intrinsic side of the motivation continuum because the motivation is altruistic in nature (Deci \& Ryan, 2000; Ryan et al., 1996; Vansteenkiste et al., 2006). 
Therefore, we might expect to see a positive association between the motivation to give back and the outcome variables and a negative association between the motivation to keep up and the outcome variables. The results, however, while not significant, indicated a generally negative association between relatedness needs to home and the outcome variables when other moderating variables were not introduced.

One reason for this conflicting finding might be explained by examining race/ethnicity as a moderating variable. White students who indicated that they were motivated to attend college to give back to their home communities indicated less intention to persist than students of color who indicated the same motivation for attending college. This result suggests that altruism, or the motivation to attend college to be able to give back to one's home community, may be a more powerful academic motivator for students of color than for White students. It is also possible, however, that participants understood "giving back" as a kind of obligation that may have represented a more introjected than fully integrated value (Deci \& Ryan, 1991).

The differences that emerged between White students and students of color with regard to the relationships between giving back and the academic outcomes may be due, in part, to differences in cultural orientation. Guiffrida (2006, 2009) has theorized that students who come from and have internalized collectivist cultural orientations may derive their most salient academic motivation from the desire to give back to others from their home community, which can include providing financial assistance, using their education to make changes in their home community, or by raising the status of their home communities through their academic success. Students who have internalized more individualist cultural orientations, according to Guiffrida, are likely to be motivated to succeed academically by more extrinsic reasons, such as obtaining a prestigious, high-paying job after graduation. Future research is needed to identify whether and how cultural orientations impact the relationships between motivational orientations and college academic outcomes.

\section{IMPLICATIONS, CONCLUSIONS, AND LIMITATIONS}

The results of this study indicate that potentially important relationships exist between student motivational orientation and academic achievement and intentions to persist. Students who were motivated to attend college to fulfill intrinsic needs for autonomy and competence showed higher GPAs and intentions to persist than students who were less motivated to attend for these reasons. This finding supports Guiffrida's $(2006,2009)$ assertion regarding the need for Tinto's (1993) theory to recognize the centrality of student motivational orientation to the student success/departure process.

This finding also has important implications for student and academic affairs practice. Student affairs practitioners and faculty who are aware of the salient influence of motivational orientation on academic achievement can foster student success by engaging with students in autonomy-supportive ways. For example, faculty can utilize classroom pedagogies that allow students maximum autonomy with regard to topics of study and course assignments. Additionally, student affairs professionals can foster intrinsic motivation among their students by providing early comprehensive career counseling and advising that allows students to identify academic courses and majors that appeal to their intrinsic interests. Counseling and advising services should also assist students in selecting the service activities and other extracurricular programs that appeal to their intrinsic needs for autonomy and competence. 
At the same time, student affairs professionals must recognize that some students, especially those from low-income households, can also derive motivation to succeed at college from the desire to obtain a well-paying job upon graduation. These low-income students are likely to benefit from a system of student support that fosters intrinsic motivation while also acknowledging their desire to improve their financial situations through their academic success. Future research is needed to understand ways in which this can be done without undermining their intrinsic motivation, given the extensive literature indicating that emphasis on rewards typically undermines intrinsic motivation (Deci, Koestner, \& Ryan, 1999).

The results of the current study also suggest that the relationship between relatedness motivation and academic success is much more complex than it is for either autonomy or competence. Further, the results indicate that demographic variables such as SES, gender, and race/ethnicity moderate the relationships between motivation and academic achievement and persistence. Because this is the first SDT study that we are aware of that has included the construct of relatedness and the above mentioned demographic variables, these findings will likely contribute, from a theoretical standpoint, to a better understanding of the relationships between intrinsic motivation and academic success.

The findings with regard to relatedness motivation are also useful to student affairs practitioners and faculty members. Student affairs professionals who are armed with an understanding of the complex relationship between relatedness motivation and academic success will be able to assist their students in balancing relationships with others in college in ways that foster student success. For example, student affairs professionals, while encouraging all students to become engaged with college peers, should also caution students whose motivation for attending college is strongly focused on peer relationships about the potential academic perils associated with extensive socializing with peers. Findings from the current study suggest this may be especially important to recognize in male students, who appear to be at a higher risk than females for prioritizing relationships with peers to the point that the relationships hinder their academic achievement. These findings might also be useful in understanding the disproportionately high alcohol use among college males (Wall, 2007). Future research is needed to better understand potential differences that may exist between the ways in which men and women engage with college peers to fulfill relatedness needs and the implications of these relationships on academic achievement and persistence.

Additionally, student affairs professionals and college faculty who are aware of students' motivational orientations with regard to relatedness needs with faculty and staff will be better able to identify students who need additional encouragement to seek out relationships with faculty and staff and provide them strategies for forming and maintaining these crucial relationships. Students who are not motivated to attend college by the need to connect with college faculty, advisors, counselors, or other student affairs personnel are likely at a higher risk of falling between the cracks of college and university student support structures than those students who arrive at college with these motivational orientations. The NRC-Q (Guiffrida et al., 2008) may provide one means for faculty and student affairs professionals to identify these high-risk students in order to reach out to them early as a means of facilitating their connections with college faculty and staff.

Finally, student affairs professionals and college faculty must be aware of the complex ways in which motivations derived 
from relatedness needs to home can impact academic achievement and persistence. In particular, the results indicate that students of color, perhaps most especially those who have internalized more collectivist cultural orientations, may derive their most powerful motivation for succeeding in college based on a desire to give back to their home communities as a way to fulfill their relatedness needs, although this assertion needs to be investigated more thoroughly. Student affairs professionals and faculty members who are aware of this powerful means of academic motivation can provide advising and counseling that seeks to reinforce this altruistic value as a means of facilitating academic success.

While the results of this study provide an important starting point for understanding relationships between motivational orientation and academic achievement and persistence, several limitations should be noted. First, the study did not employ a random sample design, which may have resulted in a systematic response bias. While the sample was generally well distributed across several dimensions of demographic variability, there was an overrepresentation of high-achieving students in the sample. Second, the study used selfreport GPA rather than examining actual college records; while self-report GPA is one of the most reliable forms of self-report data used in college student research (see Kuncel et al. 2005), the possibility of students misreporting their grades still exists. In particular, as Kuncel et al. (2005) reported, the strongest possibility for error is for lower-achieving students to report inflated grades, which may have contributed to the overrepresentation of seemingly high-achieving students in the sample. Third, the study tested intention to persist rather than actual persistence. While intention to persist has been shown to be a strong predictor of actual persistence (Vallerand et al., 1997), future research utilizing a longitudinal design is needed to assure actual persistence data are obtained. Fourth, the study included students from only two institutions (a community college and a 4-year liberal arts college), both of which were located in the Northeastern region of the United States. Additional research is needed to test the model at different types of institutions (including research institutions) and in other locations, including institutions located outside of the United States. Fifth, because of the relatively small sample of students of color, we condensed students from the various ethnic/racial groups of color together as one group in our analysis, which did not allow the potential variations within each ethnic/racial group to emerge. Future research conducted with larger samples of students of color is needed to identify potential variations that may exist among students from varying ethnicl racial groups.

Additionally, the relatively low response rate indicates the possibility for nonresponse bias; however, it is important to note that the strength of these relationships was stronger than other studies that have attempted to isolate variables related to academic achievement and persistence (see Braxton \& Lee, 2005; Braxton, Milem, \& Sullivan, 2000) and the findings often reached levels of statistical significance, which was the threshold used by Braxton and Lee in their meta-analysis to test the propositions of Tinto's (1993) theory. While future research is needed to confirm the findings from this study, the results provide a valuable first step toward understanding relationships between college student motivational orientation and academic achievement and persistence.

Correspondence concerning this article should be addressed to Douglas A. Guiffrida, Associate Professor, Warner Graduate School of Education and Human Development; Douglas.Guiffrida@Rochester.edu 


\section{REFERENCES}

Astin, A. W. (1996). Involvement in learning revisited: Lessons we have learned. Journal of College Student Development, 37, 123-134.

Bentler, p. M. (1990). Comparative fit indexes in structural models. Psychological Bulletin, 107, 238-246.

Betts, J. R., \& Morell, D. (1999). The determinants of undergraduate grade point average: The relative importance of family background, high school resources and peer group effects. Journal of Human Resources, 34, 268-293.

Bowen, W. G., \& Bok, D. (1998) The shape of the river. Princeton, NJ: Princeton University Press.

Braxton, J. M., \& Lee, S. D. (2005). Toward reliable knowledge about college student departure. In A. Seidman (Ed.), College student retention: Formula for student success (pp. 107-128). Westport, CT: Praeger.

Braxton, J. M., Milem, J. F., \& Sullivan, A. S. (2000). The influence of active learning on the college student departure process: Toward a revision of Tinto's theory. Journal of Higher Education, 75, 569-590.

Byrne, B. M. (2001). Structural equation modeling with AMOS: Basic concepts, applications, and programming. Mahwah, NJ: Lawrence Erlbaum Associates.

Chirkov, V. I. (2009). A cross-cultural analysis of autonomy in education: A self-determination theory perspective. Theory and Research in Education, 7, 253-262.

Côté, J. E., \& Levine, C. (1997). Student motivations, learning environments, and human capital acquisition: Toward an integrated paradigm of student development. Journal of College Student Development, 38, 229-243.

Deci, E. L., Koestner, R., \& Ryan, R. M. (1999). A metaanalytic review of experiments examining the effects of extrinsic rewards on intrinsic motivation. Psychological Bulletin, 125, 627-668.

Deci, E. L., Koestner, R., \& Ryan, R. M. (2001). Extrinsic rewards and intrinsic motivation in education: Reconsidered once again. Review of Educational Research., 71, 1-27.

Deci, E. L., \& Ryan, R. M. (1991). A motivational approach to self: Integration in personality. In R. Dienstbier (Ed.), Nebraska Symposium on Motivation: Vol. 38. Perspectives on motivation (pp. 237-288). Lincoln, NE: University of Nebraska Press.

Deci, E. L., \& Ryan, R. M. (2000). The "what" and "why" of goal pursuits: Human needs and the self-determination of behavior. Psychological Inquiry, 11, 227-268.

Dey, E. L. (1997). Working with low survey response rates: The efficacy of weighting adjustments. Research in Higher Education, 38(2), 215-227.

Greenlaw, C., \& Brown-Welty, S. (2009). A comparison of web-based and paper-based survey methods: Testing assumptions of survey mode and response cost. Evaluation Review, 33, 464-480.

Guiffrida, D. A. (2006). Toward a cultural advancement of Tinto's theory. Review of Higher Education, 29, 451-472.

Guiffrida, D. A. (2009). Theories of human development that enhance an understanding of the college transition process. Teachers College Record, 111, 2419-2443.

Guiffrida, D. A., \& Douthit, K. Z. (2010). The African American college student experience at predominantly White institutions: Implications for school and college counselors. Journal of Counseling and Development, 88, 311-318.

Guiffrida, D. A., Gouveia, A., Wall, A., \& Seward, D. X. (2008). Development and validation of the Need for Relatedness at College Questionnaire (NRC-Q). Journal of Diversity in Higher Education, 1(4), 251-261.

Hardre, p. L., \& Reeve, J. (2003). A motivational model of rural students' intentions to persist in, versus drop out of, high school. Journal of Educational Psychology, 95, 347-356.

Kuncel, N., Crede, M., \& Thomas, L. (2005). The validity of self-reported grade point averages, class ranks, \& test scores: A meta-analysis and review of the literature. Review of Educational Research, 75(1), 63-82.

Meyers, L. S., Gamst, G., \& Guarino, A. J. (2006). Applied multivariate research: Design and interpretation. Thousand Oaks, CA: SAGE.

Mortenson, T. (2005). Measurements of persistence. In A. Seidman (Ed.) College student retention: Formula for student success, (pp. 31-60). Westport, CT: Praeger.

Mortenson, T. (1993, September). Family income and backgrounds continue to determine chances for baccalaureate degree in 1992. Postsecondary Education Opportunity, 16, 1-7.

Nora, A., Barlow, E., \& Crisp, G. (2005). Student persistence and degree attainment beyond the first year of college: The need for research. In A. Seidman (Ed.), College student retention: Formula for student success, (pp. 129-154). Westport, CT: Praeger.

Pascarella, E. T., \& Terenzini, p. T. (2005). How college affects students: A third decade of research. San Francisco, CA: Jossey-Bass.

Phinney, J. S., Dennis, J., \& Osorio, S. (2006). Reasons to attend college among ethnically diverse college students. Cultural Diversity and Ethnic Minority Psychology, 12, 347366. doi: 10.1037/1099-9809.12.2.347

Reason, R. D. (2009). An examination of persistence research through the lens of a comprehensive conceptual framework. Journal of College Student Development, 50, 659-682.

Reeve, J., Deci, E. L., \& Ryan, R. M. (2004). Self-determination theory: A dialectical framework for understanding sociocultural influences on student motivation. In D. M. McInerney \& S. van Etten (Eds.), Big theories revisited (pp. 31-60). Greenwich, CT: Information Age Publishing.

Ryan, R. M., \& Lynch, M. F. (2003). Motivation and classroom management. In R. Curren (Ed.), A companion to the philosophy of education (pp. 260-271). Oxford, England: Blackwell.

Ryan, R. M., \& Powelson, C. L. (1991). Autonomy and relatedness as fundamental to motivation and education. Journal of Experimental Education, 60(1), 49-66.

Ryan, R. M., Sheldon, K. M., Kasser, T., \& Deci, E. L. (1996). All goals are not created equal: An organismic perspective on the nature of goals and their regulation. In p. M. Gollwitzer \& J. A. Bargh (Eds.), The psychology of action: Linking cognition and motivation to behavior (pp. 7-26). New York, NY: Guilford.

Sax, L. J., Gilmartin, S. K., \& Bryant, A. N. (2003). Assessing response rates and nonresponse bias in web and paper surveys. Research in Higher Education, 44, 409-432.

Solomon, D. J. (2001). Conducting web-based surveys. Practical Assessment Research and Evaluation, 7(19). Retrieved August 29, 2007, from http://Pareonlin.net/getvn.asp? $v=7 \& n=19$ 
Stage, F. K. (1989). Motivation, academic and social integration, and the early dropout. American Educational Research Journal, 26, 385-402.

Tinto, V. (1993). Leaving college: Rethinking the causes and cures of student attrition (2nd ed.). Chicago, IL: University of Chicago Press.

United States Department of Education. (1998). First-generation students: Undergraduates whose parents never enrolled in postsecondary education. NCES 980082. Washington, DC: National Center for Educational Statistics.

Upcraft, M. L., \& Wortman, T. I. (2000). Web-based data collection. In J. H. Schuh \& M. L. Upcraft (Eds.), Assessment practice in student affairs: An applications manual. San Francisco, CA: Jossey-Bass.

Vallerand, R. J., \& Bissonnette, R. (1992). Intrinsic, extrinsic, and amotivational styles as predictors of behavior: A prospective study. Journal of Personality, 60, 599-620.
Vallerand, R. J., Fortier, M. S., \& Guay, F. (1997). Selfdetermination and persistence in a real-life setting: Toward a motivational model of high school dropout. Journal of Personality and Social Psychology, 72, 1161-1176.

Vallerand, R. J., Pelletier, L. G., Blais, M. R., Brière, N. M., Senècal, C., \& Vallières, E. F. (1992). The Academic Motivation Scale: A measure of intrinsic, extrinsic, amotivation in education. Educational and Psychological Measurement, 52, 1003-1017.

Vansteenkiste, M., Lens, W., \& Deci, E. L. (2006). Intrinsic versus extrinsic goal contents in self-determination theory: Another look at the quality of academic motivation. Educational Psychologist, 41, 19-31.

Wall, A. (2007). Evaluating technology delivered health education: The case of AlcoholEdu. NASPA Journal, 44, 692-714. 